\title{
MYTHOS, TECHNE Y LOGOS: APROXIMACIONES AL ORI- GEN DE LA CIENCIA OCCIDENTAL A TRAVÉS DE LAS OBRAS DE HOMERO Y HESÍODO
}

\author{
Hernández Conesa, J. M. *, Moral de Calatrava, P. **, \\ Caballero Gómez, $\mathrm{M}^{\mathrm{a}}$.V. ${ }^{* * *}$
}

* Catedrática de Escuela Universitaria. Departamento de Enfermería. Miembro del grupo de investigación EYPSE. Sección : Athenea. Universidad de Murcia.

** Profesora Titular de Escuela Universitaria. Departamento de Enfermería. Miembro del grupo de investigación EYPSE. Sección Athenea. Universidad de Murcia.

*** Profesora de la Universidad Católica de Murcia. Miembro del grupo de investigación EYPSE. Sección Athenea de la Universidad de Murcia.

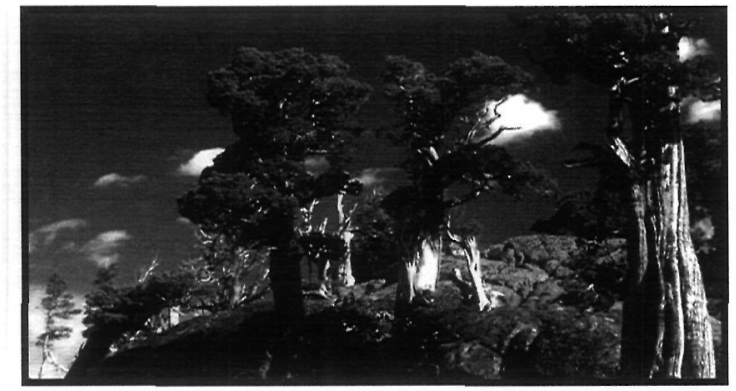

MYTHS, TECHNO AND LOGOS: APROACHING THE ORIGIN OF OCCIDENTAL SCIENCE

THROUGHOUT HOMER AND HESIOD

\section{ABSTRACT}

$\mathrm{T}$ Thought about the origins of Occidental Science take us back to Greece in VII and VI centuries b. C. Being the most splendour century the $\mathrm{V}$ century, well known as Pericles's century. It is there were first traces of occidental literature were found and protected. Those literary texts, root of measure and principles of reason and freedom are the basic foundation not only for artistic and literary creation purposes but capital works for meaning, reason for the origin of Occidental Science.

Starting from a pre-scientific thought, means of influence in the origin of rational thought and thus scientific thought, are here analysed. The fundamental literary works were considerations here stated are based on are, on the one side: The Iliad and
The Odyssey by Homer, and on the other side: Cosmogony and The works and the days by Hesiod. Differences and similarities of content in a sociopolitical context between those days and presently have been considered, as well as religious concepts - so much relevant and connected to Science in those historical dates - whose interest for our purposes forces our deepening in origins and postulates, which, to a certain extent, are still in force.

\section{RESUMEN}

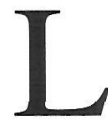

a reflexión acerca del origen de la Ciencia Occidental nos remonta a la Grecia de los siglos VII y VI a. d. C cuyo máximo esplendor lo alcanzó en el siglo $\mathrm{V}$, también conocido como el siglo de Pericles. Allí, efectivamente, hallamos los primeros textos conservados de la literatura occidental, y a través de los cuales se analizarán las obras capitales en donde se encuentra el germen de la medida y los principios de la razón necesaria y de libertad que se constituyen en los fundamentos propios no sólo de la creación artística y literaria sino del significado, razón de ser y origen de la Ciencia Occidental.

En este artículo se parte de un pensamiento precientífico y se analizan los medios por los que influyeron en el origen del pensamiento racional, y por ende científico. Las obras literarias fundamentales en las que se apoyan estas reflexiones son de una parte La Iliada y La Odisea de Homero y de otra la Cosmogonía y Los trabajos y los días de Hesíodo, a las que se ha aplicado un análisis de las características narrativas y de contenido en el con- 
texto sociopolítico del momento sin obviar las concepciones religiosas que dotaron a este momento histórico de una relevancia en el significado de la Ciencia digno de ser destacado, por el interés que para nosotros supone el interiorizar su origen y sus postulados más firmes, y que, en cierta medida, aún siguen teniendo vigencia.

\section{CONSIDERACIONES PRELIMINARES}

Con el propósito de comprender las razones que dieron origen al pensamiento científico hemos de sumergirnos en las profundidades de la Filosofía griega pues, en cierto sentido que analizaremos, se constituye en una novedad absoluta. Tener presente este hecho es crucial para comprender las razones por las que la civilización Occidental, bajo el impulso de los griegos, asumió una dirección completamente distinta de la Oriental. De hecho, no en todas las culturas se hace posible la Ciencia. Hay principios que convierten en estructuralmente imposible el nacimiento y el desarrollo de determinadas concepciones, y existen incluso ideas que impiden que la Ciencia en su conjunto florezca de acuerdo a las nociones que fundamentan a la Ciencia tal y como ahora la conocemos.

Ahora bien, la Filosofía griega, gracias a sus categorías racionales, no sólo ha permitido el nacimiento de la misma sino que en cierto sentido la ha engendrado. Admitir esto significa reconocer a los griegos el mérito de haber aportado una contribución realmente excepcional a la Historia de las Civilizaciones occidentales. Para analizar las condiciones que favorecieron el surgimiento de la Filosofía y de la Ciencia en Grecia hemos tomado como referencias principales las obras de Homero y Hesíodo, las formas religiosas y las condiciones sociopolíticas del momento histórico en el que nos encontramos, consideradas como la tierra fértil de la que nació el pensamiento científico. En las creaciones literarias sus autores, aunque utilizan herramientas intelectuales como la intuición y la imaginación, persiguen objetivos que también son propios de la Filosofía. De forma análoga, la religión aspira a alcanzar, a través de representaciones no conceptuales y de fe, determinados objetivos que la Filosofía busca discernir mediante los conceptos y la razón, pero no menos importantes son las condiciones sociales, económicas y políticas que a menudo condicionan el surgimiento de determinadas ideas y que, en el mundo griego en particular, determinaron la creación de las primeras formas de libertad institucionalizada.

\section{EL PENSAMIENTO PRECIENTÍfICO EN LAS OBRAS DE HOMERO Y HESIODO: SU HERENCIA EN EL PENSAMIENTO CIENTÍFICO GRIEGO}

Dadas las particularidades que contienen los poemas homéricos algunos ya proponen que resultarán esenciales para la creación de la Filosofía. Los especialistas han hecho notar que los poemas de Homero, aunque están repletos de imaginación, de situaciones y de acontecimientos fantásticos, casi nunca entran en la descripción de lo monstruoso y de lo deforme, característica que induce a pensar que la imaginación homérica ya está estructurada de acuerdo a un sentido de la armonía, de la proporción, del límite y de la medida. Todos estos factores serán elevados por la Filosofía al rango de principios ontológicos. Además, se ha advertido que el arte de la motivación constituye en Homero una auténtica constante. El poeta no se limita a narrar una serie de hechos, sino que investiga también sus causas y sus razones aunque lo hace desde un nivel mítico y fantástico. En Homero la acción no se "extiende como una desmadejada sucesión temporal: a ella se aplica, en todo momento, el principio de razón suficiente, cada acontecimiento recibe una rigurosa motivación psicológica" según apunta W. Jaeger. Este modo poético de contemplar las razones de las cosas prepara aquella mentalidad que en Filosofía llevará a la búsqueda de la causa y del principio, del "porqué" último de las cosas.

Otro rasgo destacable de la epopeya homérica, por su herencia en la generación del conocimiento científico, consiste en tratar de presentar la realidad en su integridad, aunque sea de forma mítica: dioses y hombres, cielo y tierra, guerra y paz, bien y mal, alegría y dolor, esto es la totalidad de los valores que rigen la vida de los hombres y que está emblemáticamente representado en el escudo de Aquiles. Así pues, Homero representa la realidad proporcionando explicaciones causales a los hechos que relata y utilizando para ello primero el análisis de los elementos para, con ello, construir una explicación armoniosa y sintética de lo acontecido. 
De otra parte, en la Teogonía de Hesíodo, que esboza una síntesis de toda una serie de materiales preexistentes, se relata el nacimiento de todos los dioses, y puesto que muchos de ellos se identifican y coinciden con partes concretas del universo y con fenómenos cósmicos, la "teogonía" termina por convertirse en "cosmogonía", es decir, en una explicación mítica, poética y fantástica de la génesis del universo y sus fenómenos, a partir del Caos originario, que fue el primero en aparecer. Este poema allanó el camino a la cosmología filosófica posterior, que abandonando la fantasía, buscará mediante la razón el primer principio de origen a todo.

El propio Hesíodo, con su otro poema, Los trabajos y los días, imprime en la mentalidad griega algunos principios de gran importancia para la constitución de la ética filosófica y, más en general, del pensamiento filosófico antiguo. Se exalta la justicia como valor supremo y se condena explícitamente la superstición como medio que proporciona unas condiciones de vida adecuadas a la naturaleza humana. "Presta oídos a justicia y olvida del todo la superchería", afirma Hesíodo . La Naturaleza para Hesíodo era considerada un orden regular y constante y, por lo tanto, cognoscible a través de la razón. El Cosmos era un universo ordenado sometido al orden y la medida y se contraponía al Caos caracterizado como indeterminado y carente de orden.

"Mucho antes de todas las cosas existió el Caos; después la Tierra espaciosa. Y el amor, que es lo más hermoso de todos los Inmortales" .

En lo referente a la religión, como segundo elemento al que hay que referirse para entender la génesis de la filosofía griega, se hace preciso distinguir entre la religión pública, cuyo modelo es la representación de los dioses y del culto que nos brinda Homero, y la religión de los misterios. Entre ambas formas de religiosidad existen numerosos elementos comunes como una concepción politeísta, pero también hay diferencias importantes, que en algunos puntos son relevantes y que básicamente se manifiestan en la concepción del hombre, el sentido de la vida y de su destino último. Ambas creencias pueden considerarse como antítesis una de otra, si bien es cierto que ambas formas de religión son muy importantes para explicar el nacimiento de la Filosofía aunque, desde ciertos puntos de vista, la segunda posee una especial importancia.

Comencemos por mencionar algunos rasgos esenciales de la primera forma de religión. Tanto para Homero como para Hesíodo, que constituyen el punto de referencia para las creencias propias de la religión pública, puede decirse que todo es divino, porque todo lo que sucede se explica en función de las intervenciones de los dioses. Los fenómenos naturales son provocados por númenes: Zeus lanza rayos y truenos desde el Olimpo, el tridente de Poseidón provoca las tempestades marinas, el sol es transportado por el dorado carro de Apolo y así sucesivamente. Además, la vida colectiva de los hombres, la suerte de las ciudades, las guerras y las paces son imaginadas como vinculadas a los dioses de un modo no accidental y, en ocasiones, realmente esencial. No obstante, todo lo que se pide al hombre es que haga en honor de los dioses aquello que es conforme a la propia naturaleza.

La primera filosofía griega fue tan naturalista como la religión pública griega, y la referencia a la Naturaleza se convirtió en una constante del pensamiento griego a lo largo de todo su desarrollo histórico. Sin embargo, la religión pública no fue sentida por todos los griegos como plenamente satisfactoria y este factor hizo que se desarrollara, en círculos restringidos, los misterios que además de poseer creencias específicas -encuadradas en el politeísmo general- contaba con prácticas que le eran propias. Sin el Orfismo es imposible explicar a Pitágoras, a Heráclito o a Empédocles, y sobretodo no se explicaría una parte esencial del pensamiento de Platón y, de toda la tradición filosófica que se derivaría de el. La reflexión sobre la Naturaleza y la regularidad de sus fenómenos están presentes en el orfismo, la religión dionisiáca y el pitagoreísmo de tal modo que está inclinada a la explicación prodigiosa y misteriosa de todos los "milagros" del cuerpo humano .

Hemos de contemplar que los griegos no tuvieron libros sagrados, verdad revelada, no poseyeron una dogmática fija e inmodificable. En Grecia no pudo ni siquiera subsistir una casta sacerdotal que custodiase el dogma. Por tal motivo, los estudiosos subrayan con toda justicia esta circunstancia favorable, para el desarrollo de la Ciencia, que no tiene ningún paralelo en la antigüedad . 
DEL PENSAMIENTO PRE-LÓGICO AL PENSAMIENTO CIENTÍFICO: EL NACIMIENTO DEL OBJETO DE ESTUDIO DE LA CIENCIA

Mientras que en la Ilíada se describen con precisión todo tipo de heridas y enfermedades provocadas por causas externas y visibles, la Odisea evidencia la parte misteriosa de las enfermedades humanas que carecen de causas visibles. Esta dualidad contemplativa y explicativa de la naturaleza del hombre por parte de Homero se manifestó también en la sociedad griega que conoció la convivencia entre una medicina mágica y otra racional. Sin embargo, a pesar de la permisibilidad de las escuelas científicas con la existencia de las corrientes explicativas mágicas, los filósofos griegos no promovieron a las técnicas a rango de aplicaciones de la ciencia, sino que se constituyeron en un sistema de aplicaciones tradicionales y habilidades prácticas que no están sujetas ni a la reflexión crítica ni a la innovación. Estas dos características pueden ser consideradas esenciales para comprender las distintas actitudes de la Ciencia Griega ante dos tipos de conocimiento no científicos: el religioso y el técnico. Mientras que el primero era capaz de proporcionar explicaciones a los fenómenos que el hombre admiraba, el conocimiento técnico no les parecía más que la mera aplicación de los descubrimientos científicos.

Sólo así puede comprenderse por qué Platón reconoce el papel que pueden desempeñar en el proceso terapéutico los encantamientos y los conjuros al tiempo es capaz de sostener que el técnico utiliza la ciencia sólo como un medio y que, a causa de su formación, tan sólo puede servirse de un material científico relativamente bajo . Platón distingue entre el saber hacer, la técnica, y la ciencia que tiene sus propias exigencias de exactitud rigurosa, sus reglas demostrativas y un lenguaje particular lo que la coloca en posición de superioridad sobre la técnica. La ciencia al haber alcanzado su objeto de estudio propio, que no es otro sino la comprensión universal a través del razonamiento, se separa de la técnica que se basa en un conocimiento sensible de los fenómenos, frente al conocimiento inteligible propio del científico, y se interesa por los resultados sin prestar atención al medio por el cual se han conseguido .
En el siglo VII, con la aparición de las Escuelas Jónicas, la Ciencia toma conciencia de sí misma abandonado la idea de la adquisición exclusiva del saber por la coordinación de los conocimientos que posee. Los griegos heredaron nociones acumuladas por la experiencia milenaria y transmitidas por Egipto y Oriente, pero sólo su esfuerzo permitió que la Ciencia se convirtiera en una disciplina autónoma. De una parte se libera de la religión y se desprende de la magia, y por otra se levanta por encima de las técnicas. Crearon un conocimiento reflexivo que era capaz de pensarse a sí mismo, que comprendía tanto los hechos que registraba como las verdades que aprehendía y esta vertiente explicativa y ontológica es una creación del genio helénico. La ciencia griega quiere dar razón a las apariencias, posee una finalidad teórica que permite afirmar que la Ciencia nació en Grecia y que fue muy superior a la Oriental.

Sin duda, las condiciones sociales, políticas y económicas que disfrutaron favorecieron todo el desarrollo del pensamiento griego. Los demócratas atenienses perseguían, de acuerdo a las concepciones de Salón y Clístenes, dar al pueblo la soberanía por lo que partieron de principios tales como igualdad ante la ley, libertad individual y filantropía. La comunidad -oikia- forma parte de la polis constituyéndose como la molécula de la comunidad política, de tal forma que el grupo doméstico no se sustrae al orden del logos y de la ley . De esta forma podríamos afirmar que La capital de la filosofía griega fue la capital de la libertad que conquistaron. Se crearon escuelas de pensamiento que influyeron en la cosmovisión de los siglos venideros, en los modos de explicación sobre el mundo, en la Patrística neoplatónica, en la Escolástica neoaristotélica, en la Ciencia Moderna -con Copérnico, Kepler y Galileo-, en la Revolución Científica -con los racionalistas y los empiristas- y en la Ciencia actual con sus disquisiciones explicativas a través de representaciones, modelos y teorías.

\section{EL NACIMIENTO DE UNA CIENCIA EN EL SIGLO XXI: CONSIDERACIONES FINALES}

Cualquier disciplina que pretenda dotarse de explicaciones científicas debe asumir los presupuestos de los que partió la Filosofía griega. El conocer los modos y procesos mediante los cuales 
construyeron el andamiaje de la Ciencia es condición necesaria para obviar asunciones internas colectivas que no han sido sometidas ni a criterios reflexivos rigurosos, ni a condiciones demostrativas pertinentes y conformes a la Filosofía de la Ciencia. Es por ello, que interiorizar la dimensión precientífica de toda actividad del hombre, lo que Platón denominó técnica, es condición inexcusable para crear las condiciones inteligibles que procuren la inmersión de una actividad profesional en el logos. Este proceso puede ser sentido por la comunidad de la que se trate como una "pérdida" que debe ser contemplada como ilusoria si el propósito que se persigue es el de la construcción científica del saber, de tal suerte que se transforma en conocimiento, en ciencia, en filosofía, en explicación propia y racional.

El recorrido histórico de la filosofía griega, lo que podría denominarse su prehistoria e historia, pone en evidencia que la explicación de los fenómenos no es condición sine qua non para considerarla científica, ya que los mitos hallados en las obras de Homero y Hesíodo son sin duda formas de explicación pre-lógica que abandonaron a favor de la lógica como elemento catalizador de la aprehensión de la realidad que analizaban. De otra parte, en la construcción del pensamiento científico griego la técnica se constituyó como un saber aplicado sin pretensiones explicativas, pues su propósito era adaptativo a las circunstancias y demandas prácticas de naturaleza social, política, económica y cultural.

\section{BIBLIOGRAFÍA}

- Giovanni Reale y Dario Antiseri, (2001), Historia Del Pensamiento Filosófico y Científico, Barcelona, Herder, Tomo I, pp.21-23. ( $1^{\mathrm{a}}$ ed. italiana 1985) y René Taton (dir), Historia general de las Ciencias, (trad. Manuel Sacristán), Barcelona, Orbis, 1988 (1ª ed. francesa 1966), T.1.

- Ibid, p. 24.

- Este presupuesto se observa especialmente en La Odisea, no obstante, también se puede justificar en algunos pasajes de La Iliada,. Homero, Ilíada, (trad. Emilio Crespo Güemes), Barcelona, Biblioteca Básica Gredos, Madrid, 2000, Homero, Odiesa, (trad. José Manuel Pabón),Madrid, Biblioteca Básica Gredos, 2000.

- Cfr W. Jaeger, La Teología de los primeros filósofos, Fondo de Cultura Económica, Madrid, 1877, W.
Jaeger, Paideia: Los ideales de la cultura griega, Fonco de Cultura Económica, 19816, y B. Snell,. Las Fuentes del pensamiento Europeo, Razón y Fe, Madrid, 1965.p 389.

- Véase en Los trabajos y los días. Los poetas líricos también fijaron de modo estable otra noción: el concepto de límite, es decir, del "ni demasiado ni demasiado poco" el concepto de la justa medida, que constituye el rasgo más peculiar de la mentalidad griega.

- Hesíodo, Teogonía, en Obras y Fragmentos, (trads. Aurelio Pérez Jiménez y Alfonso Martínez Díez), Biblioteca Básica Gredos, Madrid, 2000, v.v.115-120, p. 16. Cfr. Wilhelm Nestle, Historia del Espíritu Griego, Barcelona, Ariel, 1987 ( $1^{\mathrm{a}}$ ed. Alemana 1962), pp. 1725.

- Cfr. Bergua,J.(1979) Mitología Universal. Tomo I. Madrid. pp 213. Grimal, P. (1982) Diccionario de Mitología Griega y Romana. Barcelona. pp 413

- L. Bourgey, "La Medicina griega desde sus orígenes hasta fines de la época clásica", en AA.VV., La Ciencia Antigua y Medieval. (De los orígenes a 1450), (trad. Manuel Sacristán), T.II, Barcelona, Orbis, 1988, p.311.

- Giavanni Reale y Dario Antiseri, op. Cit, pp. 25-27. - Ibid, pp. 307-310.

- J.P. Vernant, "Remarques sur les formes et les limites de la pensée techique chez les Grecs", Revue d'historie des sciences, 1957, pp. 205-225.

- Cfr, Platón, Leyes (666 b-c, 790) y La República, $525 \mathrm{e}$.

- Cfr. Bertrand Gille, La Cultura Técnica en Grecia, Barcelona, Ediciones Juan Granica, 1985, esp. pp. 223252., para un biografía de Platón R. M. Hare, Platón, Madrid, Alianza, 1991.

- Debemos tener en cuenta que no todas las personas poseían el rango de ciudadanos, por lo que la democracia no era directa, pero tuvieron la visión preclara de crear administraciones judiciales y desarrollar actividades agrícolas y comerciales que les proporcionaron numerosos contactos con otras civilizaciones mediterráneas. Cfr. Paul Petit, Historia de la Antiguiedad, Barcelona, Labor, 1975, (1 ${ }^{\mathrm{a}}$ ed. francesa 1967), pp147164, Platón, "Apología de Sócrates", en los Diálogos (trad. J. Calonge Ruiz, E. Lledó Íñigo y C. García Gual) Biblioteca Básica Gredos, Madrid, 2000, pp. 13-51, Giulia Sissa, " La familia en la ciudad griega", en André Burguière et al, Historia de la Familia (prol. Claude Levi-Satauss y Georges Duby), t. 1, Madrid, Alianza, 1988, pp. 169-202. 